\title{
Preparation of Cellulose Esters with Aromatic Carboxylic Acids
}

\author{
Yuichi Shimizu, Atushi Nakayama*1, and Jisuke Hayashi \\ Department of Applied Chemistry, Faculty of Engineering, Hokkaido University, Sapporo, 060 Japan
}

\begin{abstract}
The preparation of cellulose esters with aromatic carboxylic (substituted benzoic) acids in the presence of $p$-toluenesulfonyl chloride $(\mathrm{TsCl})$ in pyridine ( $\mathrm{Py}$ ) was investigated. Cellulose was readily acylated with substituted benzoic acids, such as nitro-, chloro-, methyl- and methoxybenzoic acid, by use of the $\mathrm{Py} / \mathrm{TsCl} /$ acid system, and corresponding cellulose esters with high degrees of substitution (DS) were obtained. The difference among the substituents and among the isomers $(0, m$ - and $p$-isomers $)$ of the acid did not influence the reaction significantly. With an amino-substituted benzoic ( $p$-aminobenzoic) acid, the cellulose ester could not be obtained, because acylation of the $\mathrm{NH}_{2}$ group with the other $p$-aminobenzoic acid took place in preference to the $\mathrm{OH}$ group of cellulose. When the $\mathrm{NH}_{2}$ group was protected with a methyl group, on the other hand, the corresponding ester was obtained by this method.
\end{abstract}

\section{Introduction}

It is well known that organic esters of cellulose can be prepared by the use of carboxylic acid anhydride with an acid catalyst, carboxylic acid chloride in the presence of a base and carboxylic acid in combination with trifluoroacetic anhydride $[1,2]$. In any methods, either the acid anhydride or the acid chloride, i. e. an activated car. boxylic acid is necessary.

In the field of organic cellulose esters, there has been increasing interest in new methods and routes for the preparation of esters with specific acids to provide new characteristics and functions to cellulose. A method for the preparation of cellulose esters directly with carboxy. lic acids, without using acid anhydrides or acid chlorides, will lead not only to the simplification of the pre. paration and isolation of the conventional acid deriva. tives but also the preparation of cellulose esters with specific carboxylic acids whose derivatives are difficult to obtain by conventional methods.

Brewster and Ciotti [3] have shown a method for the preparation of esters from alcohols and carboxylic acids with a pyridine (Py) solution of aromatic sulfonyl chloride. We have applied this method to the preparation of

${ }^{-1}$ Present address: Technical research center, Kuraray Co., Ltd., 1621 Sakazu, Kurashiki, Okayama Pref., 710 Japan cellulose esters directly with carboxylic acids, and re. ported that this is generally applicable to the preparation of esters of higher aliphatic and benzoic acids [4] as well as cellulose acetate [5]. In addition, we have found that carboxylate salts can also be used for the esterification as same as carboxylic acids (6). In this paper we de. scribe the esterification with substituted benzoic acids by a similar system (Eq. 1).

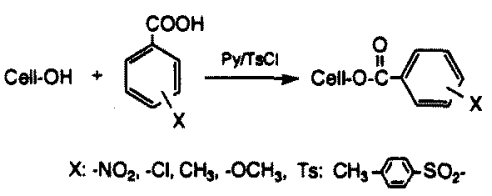

Recently, a variety of cellulose triesters are utilized as functional materials for chromatographic optical resolution [7]. This method seem to have a possibility to pre. pare new cellulose esters directly with specific acids.

\section{Experiment}

\subsection{Cellulose Sample}

Acetate grade pulp ( $a$-cellulose $96.1 \%$ ) was used as a cellulose sample. The sample was grounded in Wiley mill to less than 40 mesh before the pretreatment described below.

\subsection{Pretreatment}

Water pretreatment was employed to the cellulose to increase its reactivity. After being immersed in distilled water at room temperature for $1 \mathrm{~h}$, the sample was 
squeezed on a glass filter, rinsed completely with Py to remove the water and then squeezed again

\subsection{Acylation}

The pretreated sample $(1 \mathrm{~g})$ was introduced into a solution of $7 \mathrm{~g}$ of $p$-toluenesulfonyl chloride $(\mathrm{TsCl})$ in 30 $\mathrm{g}$ of Py. Aromatic carboxylic acid equimolar to $\mathrm{TsCl}$ was subsequently added into the solution. After the reaction for $2.20 \mathrm{~h}$ at $50{ }^{\circ} \mathrm{C}$, the reaction mixture was poured into an excess amount of ethanol. The product was collected on a glass filter, washed with ethanol, Soxhlet-extracted with ethanol for $6 \mathrm{~h}$, and dried at room temperature.

lnfrared spectra (IR) of the products were recorded on a model A202 infrared spectrophotometer (Japan Spec. troscopic Co. Ltd.) by the $\mathrm{KBr}$ disk technique. The reaction mixture was analyzed by ${ }^{1} \mathrm{H}-\mathrm{NMR}$ measurements (HITACHI R-90 FT NMR) using chlorofor $m \cdot d_{1}$ containing tetramethylsilane as an internal reference.

\section{Results and Discussion}

The property of a substituted benzoic acid depends upon the nature and position of the substituent attached to the benzene ring. Table 1 lists the substituted benzoic acids used in this work and their acidity constants [8].

Table 1 Substituted Benzoic Acids Used in This Work and Their Acidity Constants (Ka)

\begin{tabular}{lccc}
\hline \multirow{2}{*}{ Substituent } & \multicolumn{3}{c}{$K a \times 10^{-5}$} \\
\cline { 2 - 4 } & \multicolumn{1}{c}{0} & \multicolumn{1}{c}{$m$} & \multicolumn{1}{c}{$p$} \\
\hline$-\mathrm{NO}_{2}$ & 670 & 32 & 36 \\
$-\mathrm{Cl}$ & 120 & 15.1 & 10.3 \\
$-\mathrm{CH}_{3}$ & 12.4 & 5.4 & 4.2 \\
. $\mathrm{OCH}_{3}$ & 8.2 & 8.2 & 3.3 \\
\hline
\end{tabular}

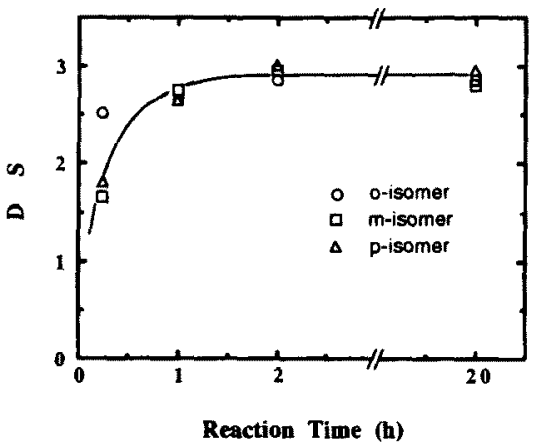

Fig. 1 Rates of esterification with $\mathrm{Py} / \mathrm{TsCl} / \mathrm{ni}$ trobenzoic acids $(0, m$ - and $p$-isomer)

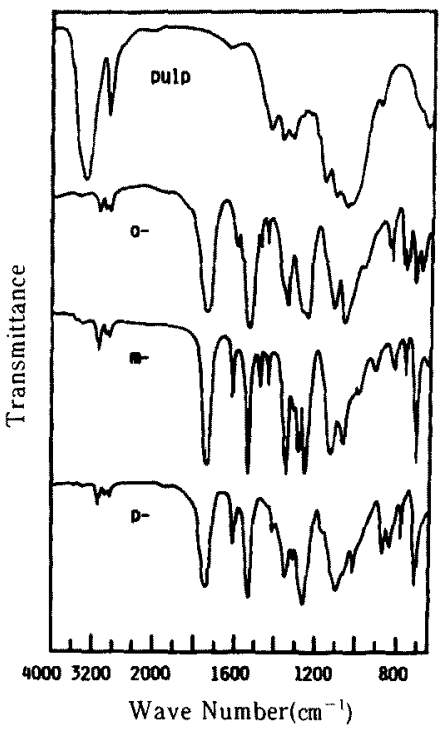

Fig. 2 IR spectra of original pulp and cellulose esters prepared with $o \cdot m$ - and $p$-nitrobenzoic acids.

Fig. 1 shows the rates of esterification with isomers of nitrobenzoic acid at $50{ }^{\circ} \mathrm{C}$. Molar ratios between $\mathrm{TsCl}$, the acid and the $\mathrm{OH}$ group of cellulose were adjusted to $2: 2: 1$ based on the results for acetylation of cellulose with the Py/ TsCl/ AcOH system [3, 4]. Degrees of substitution (DS) of the products were determined by the nitrogen content from elemental analysis. As shown in the figure, the reaction proceeded rapidly at an initial stage and DS values of the products reached almost 3 within 2 $h$ resulting in swelling and/ or dissolution of the products into the reaction mixtures. In spite of the large difference in the acidity constant between $0, m$ - and $p$-isomers, the difference in reactivity between them was not so remarkable. The reaction mixture became yellow or dark brown as the time, and ligth yellow color remained in the products prepared with $o$ - and $p$-isomers even after the purification.

Fig. 2 shows IR spectra of the products prepared with the nitrobenzoic acids for $20 \mathrm{~h}$ at $50{ }^{\circ} \mathrm{C}$ together with that of the original pulp. The products had common absorptions due to ester $\mathrm{C}=0$ (about $1750 \mathrm{~cm}^{-1}$ ) and $\mathrm{C}-0$ (about $1260 \mathrm{~cm}^{-1}$ ) stretchings, and the $\mathrm{OH}$ absorption of cellulose (about $3400 \mathrm{~cm}^{-1}$ ) was not observed. Further, absorptions arising from both the aromatic ring (C- $\mathrm{H}$ at $3000-3100 \mathrm{~cm}^{-1}$ and $\mathrm{C}=\mathrm{C}$ at $1400-1600 \mathrm{~cm}^{-}$ $\left.{ }^{1}\right)$ and the substituent $\mathrm{NO}_{2}\left(1540\right.$ and $\left.1350 \mathrm{~cm}^{-1}\right)$ were 


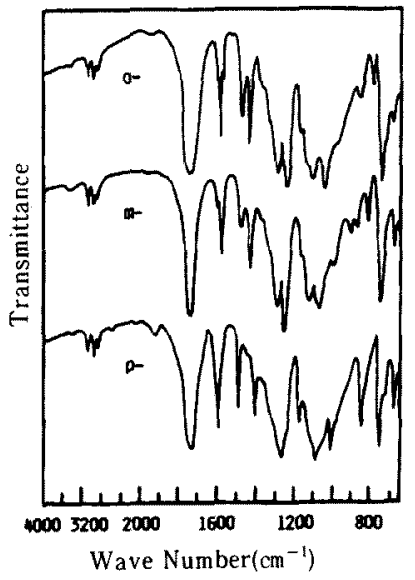

Fig. 3 IR spectra of cellulose esters prepared with 0 -, $m$ - and $p$-chlorobenzoic acids.

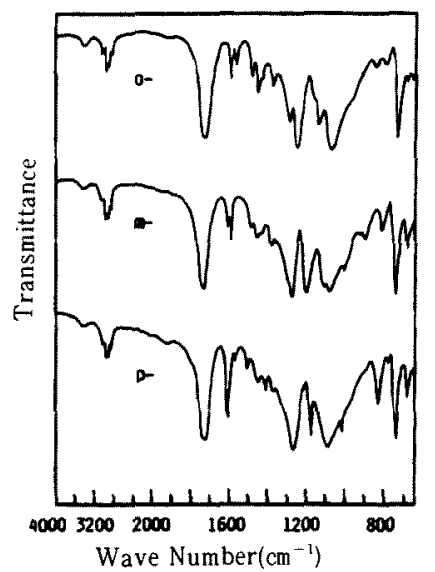

Fig. 4 IR spectra of cellulose esters prepared with $o$, $m$ - and $p$-methylbenzoic (toluic) acids.

observed in the spectra. The spectrum of the product prepared with $p$-isomer agreed well with that of the product prepared by the acid chloride method. It is known that cellulose is tosylated and chlorinated by the treat. ment with $\mathrm{TsCl}$ in Py. Howevre, there was no detectable sulfur and chlorine in the present products, and this shows that neither tosylation nor chlorination of the $\mathrm{OH}$ groups occurred on cellolose in this reaction. From these results the products were confirmed to be cellulose es. ters of corresponding nitrobenzoic acids with high DS values.

IR spectra of the products prepared with chloromethyl and methoxy-benzoic acids by the procedure same as for nitrobenzoic acids were shown in Figs. 3, 4 , and 5 , respectively. These spectra also have absorptions

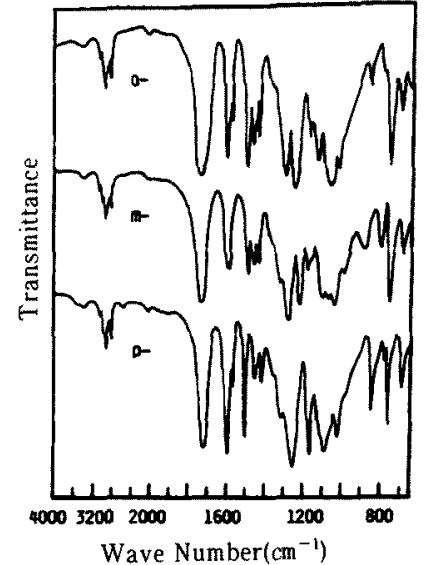

Fig. 5 IR spectra of cellulose esters prepared with 0 , $m$ - and $p$-methoxybenzoic acids

Table 2 DS Values of Cellulose Esters Prepared with Substituted Benzoic Acids ${ }^{\text {) }}$

\begin{tabular}{lccc}
\hline \multirow{2}{*}{ Substituent } & \multicolumn{3}{c}{ DS } \\
\cline { 2 - 4 } & $o-$ & $m \cdot$ & $p$ - \\
\hline. $\mathrm{NO}_{2}$ & 2.85 & 2.70 & 2.95 \\
. $\mathrm{Cl}$ & 2.90 & 2.90 & 2.80 \\
. $\mathrm{CH}_{3}$ & 2.40 & 2.60 & 2.50 \\
. $\mathrm{OCH}_{3}$ & 2.60 & 2.70 & 2.50 \\
\hline
\end{tabular}

a) Reaction Time; $20 \mathrm{~h}$.

characteristic of the ester and the aromatic ring similarly to those of the products prepared with nitrobenzoic acids. In addition, since the $\mathrm{OH}$ absorption became very weak, these products were also cellulose esters of the corresponding acids with high DS values.

The DS values of these products calculated from the elemental analysis data are summarized in Table 2 . The small differences in DS values among isomers and among substituents show that cellulose esters with high DS values can be prepared from substituted benzoic acids independent of the substituents and isomers by the Py/ $\mathrm{TsCl}$ acid system. Yields of these products corres ponded to those calculated from DS values.

The preparation of cellulose ester with $p$-aminobenzoic acid was attempted next for the introduction of an amino group to cellulose. The trial, however, was unsuccessful. The product obtained was not the ester but a mixture of unreacted pulp and the compound whose IR spectrum was shown in Fig. 6 (B). Since there are absorptions 


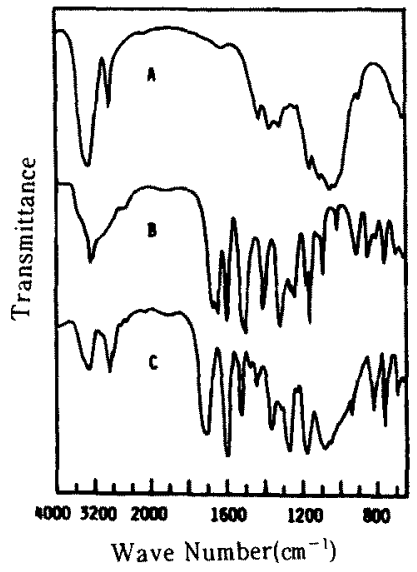

Fig. 6 IR spectra of (A) original pulp. (B) the compound obtained by $\mathrm{Py} / \mathrm{TsCl} / p$-aminobenzoic acid and (C) cellu. lose ester obtained by $\mathrm{Py} / \mathrm{TsCl} / p$ - $N, N$-dimethylamino) benzoic acid.

characteristic of N.H stretching $\left(3300 \mathrm{~cm}^{-1}\right)$, amide $\mathrm{C}=0$ stretching $\left(1650 \mathrm{~cm}^{-1}\right.$ : amide $\mathrm{I}$ absorption) and $\mathrm{N}-\mathrm{H}$ bending ( $1500 \mathrm{~cm}^{-1}$ : amide II absorption) in the spectrum, the compound seems to be an amide compound that is formed by condensation of p-aminobenzoic acid. This indicates that the acylation of the $\mathrm{NH}_{2}$ groups took place in preference to the $\mathrm{OH}$ groups of cellulose in the Py/ TsCl/ praminobenzoic acid system. Fig. 6 (C) shows the IR spectrum of the product that was prepared with $p \cdot(N$, $N$-dimethylamino) benzoic acid instead of $p$-aminobenzoic acid in the system. The absorptions due to ester group, $C$ $=0\left(1720 \mathrm{~cm}^{-1}\right)$ and $\mathrm{C}-0\left(1260 \mathrm{~cm}^{-1}\right)$ stretchings, show that the product is a cellulose ester. The DS values calculated from the elemental analysis data was 1.10 . lower than those of the esters described previously. These findings show that when the $\mathrm{NH}_{2}$ group of an amino benzoic acid was protected, the corresponding cellu lose ester could be obtained with the $\mathrm{Py} / \mathrm{TsCl} /$ acid sys. tem.

Brewster and Ciotti [ 3 ] have shown that carboxylic acids react rapidly with arylsulfonyl chloride $\left(\mathrm{ArSO}_{2} \mathrm{Cl}\right)$ in a Py solution to form symmetrical anhydrides, and that the anhydrides serve as acylating reagents of alcohols (Eq. 2).

$$
\mathrm{Py} / \mathrm{ArSO}_{2} \mathrm{Cl}
$$

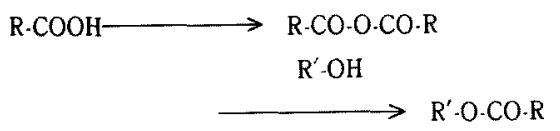

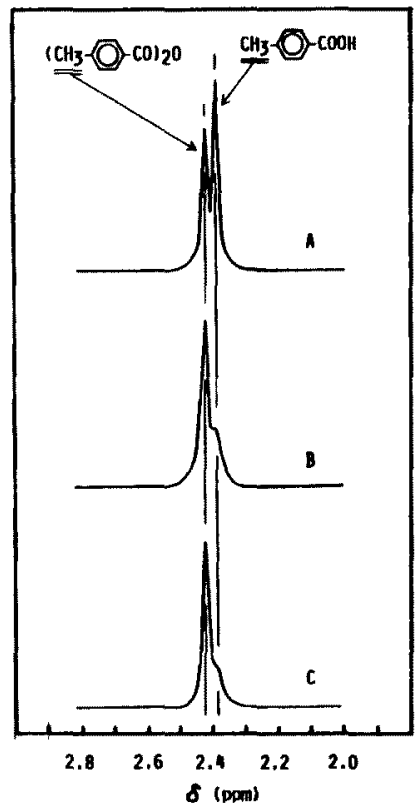

Fig. 7 'H.NMR spectra of $\mathrm{Py} / \mathrm{TsCl} / p$-toluic acid system: (A), just after the mixing; (B), after $10 \mathrm{~min}$; (C), after $1 \mathrm{~h}$ at room temperature.

Relating to this, 'H-NMR spectra were taken to examine the composition of the present system. Fig. 7 show ${ }^{1} \mathrm{H}$. NMR spectra (2-3 ppm) of Py/ benzenesulfonyl chloride $(\mathrm{BsCl}) / p$-methylbenzoic (toluic) acid system which did not include the cellulose sample. $\mathrm{BsCl}$ was used as a ArSO $\mathrm{Cl}_{2} \mathrm{Cl}$ instead of $\mathrm{Ts} \mathrm{Cl}$ because the methyl proton peak of $\mathrm{TsCl}$ overlapped with that of toluic acid in the spectra. The peak at 2.38 was assigned to the methyl protons of $p$.toluic acid based on its 'H.NMR spectrum in Py solution. We have confirmed the formation of acetic anhyd. ride in the $\mathrm{Py} / \mathrm{TsCl} / \mathrm{AcOH}$ system ( 9 ) by the ${ }^{1} \mathrm{H} \cdot \mathrm{NMR}$ measurement. Brewster and Ciotti (3) have prepared benzoic anhydride by the $\mathrm{Py} / \mathrm{BsCl} /$ benzoic acid. The peak at $2.42 \mathrm{ppm}$, therefore, is considered to be due to the methyl protons of $p$-toluic anhydride. The anhydride was formed just after the mixing of $\mathrm{Py}, \mathrm{BsCl}$ and the acid (Fig. 7 (A)), and increased with time while the acid decreased. After standing for $1 \mathrm{~h}$ at room temperature, the acid was mostly converted to the anhydride (Fig. 7 (C)). which were stable in the system thereafter. The anhyd. ride thus formed in situ will react with cellulose, leading to the ester.

Solubility of the esters obtaind in this work was in. 
Table 3 Solubility of Cellullose Esters ${ }^{\text {a) }}$ in Various Organic Solvents

\begin{tabular}{|c|c|c|c|c|c|c|c|c|c|c|c|c|}
\hline \multirow{3}{*}{ Solvent } & \multicolumn{12}{|c|}{ Solubility $^{\text {b) }}$} \\
\hline & \multicolumn{3}{|c|}{$-\mathrm{NO}_{2}$} & \multicolumn{3}{|c|}{$-\mathrm{Cl}$} & \multicolumn{3}{|c|}{$\mathrm{CH}_{3}$} & \multicolumn{3}{|c|}{. $\mathrm{OCH}_{3}$} \\
\hline & 0 & $m$ & $p$ & 0 & $m$ & $p$ & $0^{\prime \prime}$ & $m$ & $p$ & $o$ & $m$ & $p$ \\
\hline DMSO & $\triangle$ & 0 & $\Delta$ & $\Delta$ & $x$ & 0 & $\Delta$ & $\Delta$ & $x$ & 0 & 0 & $\triangle$ \\
\hline DMF & $\mathrm{O}$ & 0 & 0 & $x$ & 0 & 0 & $\triangle$ & 0 & $x$ & 0 & $\Delta$ & $\triangle$ \\
\hline Acetone & $x$ & $x$ & $x$ & $x$ & $x$ & 0 & $x$ & 0 & $\times$ & $x$ & $x$ & $x$ \\
\hline Ethyl acetate & $x$ & $x$ & $\times$ & $x$ & $\Delta$ & $\triangle$ & $\Delta$ & $\triangle$ & $\times$ & $x$ & $x$ & $x$ \\
\hline Dichloroethane & $x$ & $x$ & $x$ & 0 & 0 & 0 & $\Delta$ & 0 & $x$ & $\triangle$ & 0 & $\Delta$ \\
\hline THF & $x$ & 0 & $x$ & $\triangle$ & 0 & 0 & $\Delta$ & 0 & $x$ & $x$ & $\bigcirc$ & $\triangle$ \\
\hline Chloroform & $x$ & $\times$ & $x$ & 0 & 0 & 0 & 0 & 0 & $\times$ & $\triangle$ & 0 & $\Delta$ \\
\hline Dichloromethane & $x$ & $x$ & $\times$ & 0 & 0 & $\Delta$ & $\Delta$ & 0 & $x$ & 0 & 0 & $\triangle$ \\
\hline Ethyl ether & $x$ & $x$ & $x$ & $x$ & $x$ & $x$ & $x$ & $x$ & $x$ & $x$ & $x$ & $x$ \\
\hline Pentane & $x$ & $x$ & $x$ & $x$ & $x$ & $x$ & $x$ & $x$ & $x$ & $x$ & $x$ & $x$ \\
\hline Benzene & $x$ & $x$ & $x$ & $\Delta$ & $\Delta$ & $\Delta$ & $\Delta$ & 0 & $\times$ & $x$ & $\Delta$ & $x$ \\
\hline
\end{tabular}

a) DS values are shown in Table 2

b) $\bigcirc$. Soluble; $\triangle$, swelling and/ or partly soluble; $X$, insoluble.

vestigated and summarized in Table 3 . They were almost white except for those prepared with $o$ - and $p \cdot n i$ trobenzoic acids that were light yellow. The products prepared with nitrobenzoic acids did not show good solu. bility in the solvents in spite of their high DS values.

They were dissolved only in dimethylformamide (DMF). and the product prepared with $m$-isomer was dissolved in dimethylsulfoxide (DMSO) and tetrahydrofuran (THF). The products prepared with the other acid dissolved in several solvents, unlike those prepared with nitrobenzoic acids. On the whole, such chlorine containing solvents as dichloroethane, chloroform and dichloromethane and THF were good solvents for them. The large differences in solubility among the isomers, however, were observed for the esters. Especially, in the products prepared with methylbenzoic acids, that prepared with the $p$-isomer was entirely insoluble in any solvents used in this work. Although the cause of the differences was not clear, it may depend upon the nature of the isomer introduced because there is little difference in DS values among them.

From the solutions of the cellulose esters in THF, dich. loroethane, chloroform and dichloromethane, films were prepared by the casting method.

The $\mathrm{Py} / \mathrm{TsCl} /$ acid system is useful for the prepara tion of cellulose esters with a variety of substituted benzoic acids.

\section{Acknowledgments}

A part of this research was supported by a Grant-in. Aid for Science Research (No.02855225) from the Minis. try of Education, Japan.

\section{References}

1. E. J. Bourne, M. Stacey, J. C. Tatlow, and J. M. Tedde, J. Chem. Soc., 1949, 2976.

2. K. S. Barclay, E. J. Bourne, M. Stacey, and M. Webb, J. Chem. Soc., 1954, 1501.

3. J. H. Brewster and C. J. Ciotti, Jr., J. Am. Chem. Soc., 77, 6214 (1955).

4. Y. Shimizu and J. Hayashi, Cellulose Chem. Technol., 23, 661 (1989).

5. Y. Shimizu and J.Hayashi, Sen'i Gakkaishi, 44, 451 (1988).

6. Y. Shimizu, A. Nakayama, and J. Hayashi, Cellulose Chem. Technol., 25, 275 (1991).

7. T. Shibata, I. Okamoto, and K. Ishii, J. Liq. Chroma togr., 9. 313 (1986).

8. R. T. Morrison and R. N. Boyd, "Organic Chemistry (Fifth Edition)". Allyn and Bacon, Inc., Boston, p.839 (1987).

9. Y. Shimizu, A. Nakayama, and J. Hayashi, Proc. Hokkaido Branch, Japan Wood Res. Sac., No. 22, 63 (1990). 